\title{
Tramiprosate in mild-to-moderate Alzheimer's disease - a randomized, double-blind, placebo-controlled, multi-centre study (the Alphase Study)
}

Paul S. Aisen", Serge Gauthier ${ }^{2}$, Steven H. Ferris ${ }^{3,4}$, Daniel Saumier ${ }^{5}$, Denis Haine ${ }^{6}$, Denis Garceau, Anh Duong ${ }^{6}$, Joyce Suhy ${ }^{8}$, Joonmi Oh, Wan C. Lau, John Sampalis ${ }^{6,9}$ for the Alphase group

1University of California, San Diego, La Jolla, CA, USA

2McGill Center for Studies in Aging, Verdun, Quebec, Canada

${ }^{3}$ New York University School of Medicine, New York, NY, USA

${ }^{4}$ Nathan Kline Institute, Orangeburg, NY, USA

${ }^{5}$ Department of Neurology and Neurosurgery, McGill University, Montreal, Quebec, Canada

6JSS Medical Research, Westmount, Quebec, Canada

${ }^{7}$ BELLUS Health Inc., Laval, Quebec, Canada

8Synarc Inc., San Francisco, CA, USA

${ }^{9}$ McGill University Health Centre, Montreal, Quebec, Canada

Submitted: 1 February 2010

Accepted: 28 May 2010

Arch Med Sci 2011; 7, 1: 102-111

DOI: 10.5114/aoms.2011.20612

Copyright (c) 2011 Termedia \& Banach

\section{Abstract}

Introduction: The aim of the study was to assess the clinical efficacy, safety, and disease-modification effects of tramiprosate (homotaurine, ALZHEMEDTM) in mild-to-moderate Alzheimer's disease (AD).

Material and methods: Double-blind, placebo-controlled, randomized trial in 67 clinical centres across North America. Patients aged $\geq 50$ years, with mild-tomoderate AD (Mini-Mental State Examination score between 16 and 26) and on stable doses of cholinesterase inhibitors, alone or with memantine. Intervention: 78-week treatment with placebo, tramiprosate $100 \mathrm{mg}$ or tramiprosate $150 \mathrm{mg}$ BID. Measurements: Alzheimer Disease Assessment Scale - cognitive subscale (ADAScog) and Clinical Dementia Rating - Sum of Boxes (CDR-SB) assessments were performed at baseline and every 13 weeks. Baseline and 78-week magnetic resonance imaging (MRI) hippocampus volume (HV) measurements were conducted in a subgroup of patients.

Results: A total of 1,052 patients were enrolled and 790 (75.1\%) completed the 78-week trial. Patient discontinuation and reasons for withdrawal were similar across groups. Planned analyses did not reveal statistically significant betweengroup differences. Lack of adequate statistical validity of the planned analysis models led to the development of revised predictive models. These adjusted models showed a trend toward a treatment effect for ADAS-cog $(P=0.098)$ and indicated significantly less HV loss for tramiprosate $100 \mathrm{mg}(P=0.035)$ and $150 \mathrm{mg}(P=0.009)$ compared to placebo. The incidence of adverse events was similar across treatment groups.

Conclusions: The primary planned analyses did not show a significant treatment effect, but were confounded by unexplained variance. Post-hoc analyses showed a significant treatment-related reduction in HV loss. However, there was only a trend towards slowing of decline on the ADAS-cog and no slowing of decline on the CDRSB. These results must be interpreted in consideration of the limitations of clinical and disease-modification outcome measures and their relationship, the heterogeneity of the disease and the impact of confounding demographic and clinical variables.

Key words: tramiprosate, Alzheimer's disease, amyloid, disease-modification, volumetric MRI.

\author{
Corresponding author: \\ Anh Duong, PhD \\ JSS Medical Research Inc. \\ 4492 Ste. Catherine St. West \\ Westmount, Quebec \\ H3Z 1R7 Canada \\ Phone: +514 9346116 \\ Fax: +514 9349913 \\ E-mail: \\ aduong@jssresearch.com
}




\section{Introduction}

Current therapies for Alzheimer's disease (AD) are symptomatic with limited impact on the disease itself. Treatment that slows or stops disease progression remains an unmet need. Accumulation of the amyloid $\beta(A \beta)$ peptide is a pivotal process in the natural history of AD. Amyloid $\beta$ is generated by enzymatic cleavage of the amyloid precursor protein (APP) with subsequent formation of toxic $A \beta$ oligomers and amyloid fibrils, which are ultimately deposited as plaques in the brain [1]. This process is hypothesized to induce neurotoxic events that lead to neurovascular uncoupling, synaptic dysfunction and neuronal loss [2, 3]. Ensuing structural damage in some brain areas such as the hippocampus, as revealed by magnetic resonance imaging, may be associated with, or even precede, clinical symptoms [3]. Interventions that protect against $A \beta$-induced neurotoxicity may have therapeutic value for the treatment of AD [4].

Tramiprosate (homotaurine, ALZHEMED ${ }^{\text {TM}}$ ) is a small, orally-administered compound that binds to soluble $A \beta$ and reduces amyloid aggregation and subsequent deposition [5]. In vitro, tramiprosate provides neuroprotection against $A \beta$-induced neurotoxicity in neuronal and mouse organotypic hippocampal cultures, and reverses $A \beta$-induced long-term potentiation (LTP) inhibition in rat hippocampus [6], in part, through activation of $\beta$-aminobutyric acid A (GABA-A) receptors [7]. In vivo, tramiprosate produced dose-dependent reductions of $A \beta$ in the brain of transgenic mice (hAPP-TgCRND8) [6]. Clinical studies [8] showed that tramiprosate was safe and tolerable. In mildto-moderate $A D$ patients [8] tramiprosate also reduced $A \beta_{42}$ levels in CSF.

The objectives of the Alphase, Phase III, NorthAmerican multi-centre, randomized, double-blind, placebo-controlled study was to assess the clinical efficacy, safety, and disease-modification effects of tramiprosate in patients with mild-to-moderate AD.

\section{Material and methods}

\section{Patients}

Participants (men and women $\geq 50$ years) had a diagnosis of probable AD (DSM-IV-TR [9] and NINCDS-ADRDA [10]) and a Mini-Mental State Examination (MMSE) [11] score between 16 and 26. Laboratory assessments, electrocardiograms (ECG) and $C T / M R I$ results were compatible with probable $A D$. Patients were required to be on a stable dose of a cholinesterase inhibitor (ChEI) which may have been combined with memantine, for a minimum of four months prior to the screening visit. Stable doses ( $\geq 1$ month prior to screening) of anxiolytics, sedatives, hypnotics, antidepressants, antipsychotics, anticonvulsants, oestrogens, statins, and vitamin E ( $\leq 2050 \mathrm{IU} /$ day) were allowed. Patients with any other causes of dementia were excluded, as were those with a body mass index $<19$ or > 28, a life expectancy < 2 years, or a clinically significant and uncontrolled medical disease. The study protocol was approved by the ethics review board of each site. Written informed consent was obtained from each patient or legally authorized representative prior to study entry.

\section{Study design}

This was a randomized, double-blind, placebocontrolled, parallel-group study conducted at 67 study centres across the United States and Canada. Patients were randomized to tramiprosate $100 \mathrm{mg}$ BID, tramiprosate $150 \mathrm{mg}$ BID, or placebo BID for 78 consecutive weeks, including an 8-week dose escalation phase. Treatment was allocated according to a randomization list issued by an independent biostatistician, using a computer random number generator, and balanced to ensure a ratio of $1: 1: 1$ across groups. Study medication consisted of modified-release coated tablets, identical in external appearance and containing $50 \mathrm{mg}$ of tramiprosate or placebo. All doses were administered orally as three tablets.

\section{Procedure}

Clinical efficacy measures were Alzheimer's Disease Assessment Scale-cognitive subscale (ADAScog) [12], Clinical Dementia Rating-Sum of Boxes (CDR-SB) [13], MMSE [11], Clinical Interview Based Impression of Change-plus caregiver interview (CIBIC-plus) [14], Neuropsychiatric Inventory (NPI) [15], and Disability Assessment of Dementia (DAD) [16] scores. Disease-modification measures were volumetric magnetic resonance imaging ( $v M R I)$ of the hippocampus, whole brain and entorhinal cortex, plasma/CSF/urine $A \beta$, and CSF tau. Safety measures included Adverse Event (AE) reporting (MedDRA 9.0), vital signs, clinical laboratory parameters, ECG, and physical examinations.

Clinical and safety assessments were conducted at Baseline and Weeks 13, 26, 39, 52, 65 and 78. HV was measured at Baseline and at Week 78 in a subgroup of patients at 51 sites. The complete description of HV measurements is provided elsewhere [17]. Briefly, centralized assessment of $\mathrm{HV}$ was derived from a 1.5T T1-weighted 3-dimensional volumetric $M R$ sequence $(T R=$ 10/2160/9.5 ms, TE = 6.8/3.9/4 ms, $192 \times 256 / 192 \times$ $\times 256 / 256 \times 256$ matrix, 260/260/258 mm FOV, flip angle $=20^{\circ} / 10^{\circ} / 8^{\circ}$, slice thickness $=1.6 / 1.6 / 1.6 \mathrm{~mm}$ for GE/Siemens/Philips, respectively). HV was computed using a semi-automated atlas-based warping method [18]. 


\section{Statistical analyses}

In this report, only the ADAS-Cog, CDR-SB, and HV results will be reported as they constituted the primary clinical efficacy and disease-modification endpoints. Primary clinical efficacy endpoints were the changes from Baseline to Week 78 in ADAS-cog and CDR-SB scores. Secondary efficacy endpoints were the changes from Baseline to Weeks 13, 26, 39, and 52 in ADAS-cog and CDR-SB. Primary diseasemodification endpoints were the changes from Baseline to Week 78 in vMRI of the hippocampus.

Sample size calculations were based on the assumptions that after 78 weeks, patients on placebo would decline by a mean (SD) of 10 (8.0) points on the ADAS-cog and 3.0 (2.3) points on the CDR-SB [19]. Assuming a 25\% effect size, the study was powered to detect a difference of 2.5 points on the ADAS-cog and 0.75 point on the CDR-SB with $90 \%$ power at a two-tailed 5\% significance. Adjusting for an approximate $30 \%$ dropout rate, an enrolment of 315 patients per group was planned. For HV, sample size estimate was based on an untreated mean (SD) 5.2\% (2.5\%) annual change in HV [20-25]. In order to detect a $20 \%$ difference in the HV change between active and placebo with $80 \%$ power, at a $5 \%$ two-tailed significance, and assuming an approximate $30 \%$ patient discontinuation rate, 150 patients per group were to be enrolled in this sub-study.

\section{Planned models}

Changes from Baseline in ADAS-cog and CDR-SB scores were assessed using mixed-effect repeatedmeasures analyses of covariance (ANCOVA). These models tested for the main effects of Group (treatment arm), Visit (treatment duration) and Group $\times$ Visit $(G \times V)$ interaction, adjusted for Baseline values and Site as covariates. The $G \times V$ interaction reflected between-group differences in least-square (LS) mean changes over time. Betweengroup differences were determined using planned contrasts comparing each active treatment group to placebo with respect to the changes in ADAS-cog and CDR-SB from Baseline to Week 78 (primary clinical outcome) and from Baseline to Weeks 13, $26,39,52$, and 65 (secondary clinical outcomes). Change in $\mathrm{HV}$ was calculated by subtracting the final visit volume from the Baseline volume using the Last Observation Carried Forward approach for withdrawn patients. Differences in changes over time in HV between treatment arms were evaluated with an ANCOVA in which the dependent variable was the change in HV over the 78 Weeks of the study and the independent variables were treatment group with three levels (tramiprosate $150 \mathrm{mg}$ BID, tramiprosate $100 \mathrm{mg}$ BID, and Placebo BID), duration of follow-up (in months), Baseline HV and Site. Between-group differences in the change in $\mathrm{HV}$ were assessed with the overall F-test for treatment group while differences between each active group and placebo were assessed using planned contrasts.

\section{Adjusted models}

For all study outcomes, unanticipated and highly significant Site effects $(P<0.001)$ were detected in the planned ANCOVA models. This suggested that either a significant amount of the variability was due to differences between sites, or that "Site" was concealing confounding variables that were not accounted for in the model, contributing to poor model fit. Post-hoc analyses aimed at reducing Site effects and improving model fits were conducted. Adjusted mixed-effects multivariate models were developed using aggregate data. Additional covariates were selected using a four-step process: 1) identification of cross-sectional and longitudinal patterns in the data, 2) identification of variables which were predictors of outcome based on a statistical trend defined as a $P<0.15$, 3) selection of variables that were significant independent predictors of outcome, with a $P<0.15$ tolerance, and 4) assessment of the clinical relevance of the identified variables by an independent scientific advisory committee. The fixed effect covariates in the planned models were removed based on likelihood ratio test and information criteria improvement (Akaike and Bayesian). Once the final adjusted models were developed, treatment variables were included in a three-level linear mixed-effect model with random site-specific intercepts and slopes for ADAScog and CDR-SB, and a two-level linear mixed model with random site-specific intercepts for HV. In the adjusted models, contrasts comparing each active group to Placebo at each visit were exploratory and aimed at documenting possible trends. No adjustments for multiple comparisons were thus required. Statistical trends $(P<0.15)$ are reported.

Both planned and adjusted models were based on observed cases. Efficacy analyses were conducted in the Intent-to-Treat (ITT) population, defined as all treated patients who had a Baseline ADAS-cog or CDR-SB assessment and at least one corresponding post-Baseline assessment. Diseasemodification analyses were based on the MRI-ITT population, defined as ITT patients with a Baseline and on-treatment MRI that was valid for evaluating at least one of the targeted brain structures. Sites that recruited fewer than six patients were pooled. Twelve patients were excluded due to GCP noncompliance. Statistical analyses were performed using SAS version 9.12 .

\section{Results}

Patient disposition and baseline characteristics.

The study took place between August 2004 and February 2007. A total of 1,432 patients were 
screened, of whom 1,052 were randomized (placebo BID: $n=353$, tramiprosate $100 \mathrm{mg}$ BID: $n=352$, tramiprosate $150 \mathrm{mg}$ BID: $n=347)$ and $790(75.1 \%)$ completed the trial. Patient discontinuation and reasons for withdrawal were similar across groups. Adverse event (48.1\%) and withdrawal of consent (30.5\%) were the most frequent reasons for early discontinuation. Patient disposition is presented in Figure 1. There were no statistical differences between groups with regards to baseline and demographic characteristics (Table I).

\section{Planned analyses}

Table II summarizes results using the planned analyses. All three groups experienced an increase from Baseline to each visit in clinical scores, indicating deterioration. The planned ANCOVA model for ADAS-cog did not reveal a significant $G$ $\times \mathrm{V}$ interaction $(P=0.152)$ although planned contrast for the primary ADAS-cog outcome revealed numerically less decline at Week 78 in the $100 \mathrm{mg}$ versus placebo ( -0.70 points). Neither the planned $\mathrm{G} \times \mathrm{V}$ interaction $(P=0.573)$ nor the planned contrast for the primary CDR-SB outcome at Week 78 (100 mg vs. Placebo: $P=0.405 ; 150 \mathrm{mg}$ vs. Placebo: $P=0.837$ ) revealed a statistically significant treatment effect. Planned contrasts for the secondary ADAS-cog outcomes revealed that, relative to placebo, the $100 \mathrm{mg}$ BID group had a statistically lower change from Baseline $(P=0.027)$ at Week 26. No statistical difference relative to placebo was observed for any of the secondary CDR-SB outcomes. For HV change, the planned model showed a non-significant treatment effect $(P=0.120)$. Compared to Placebo, the $100 \mathrm{mg}$ BID group showed no volume change difference $(P=0.782)$, while a trend toward greater $\mathrm{HV}$ decrease was observed in the $150 \mathrm{mg}$ BID group $(P=0.056)$.

\section{Adjusted models}

The adjusted models (Table III) improved data fit as indicated by Aikaike Information Criteria (AIC) values of 28772.5 for the ADAS-cog and 17355.4 for

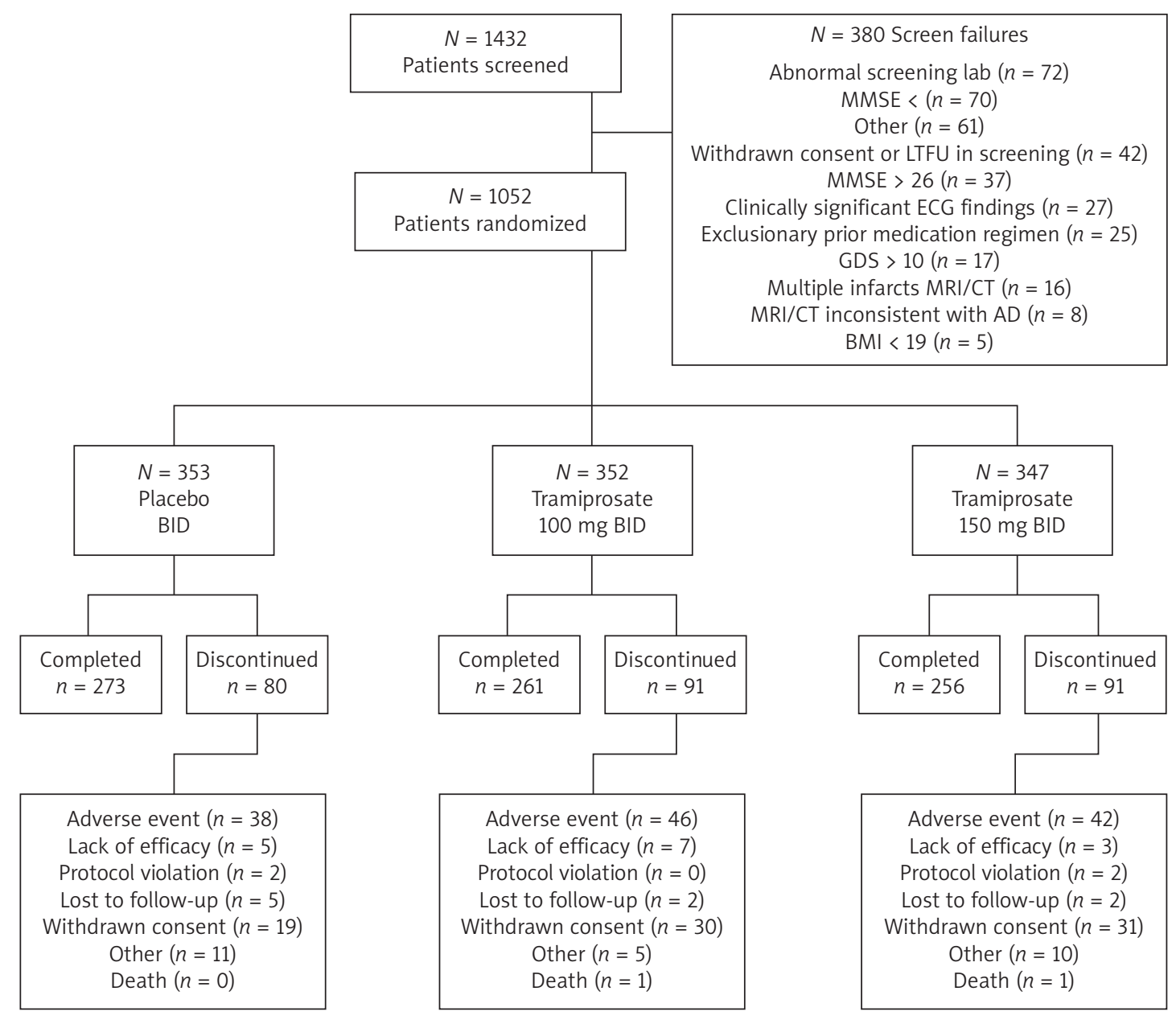

MMSE - mini-mental state exam, LTFU - lost to follow-up, GDS - Geriatric Depression Scale, BMI - body mass index

Figure 1. Patient disposition 
Table I. Demographic and baseline characteristics - ITT population

\begin{tabular}{|lcccc|}
\hline & $\begin{array}{c}\text { Placebo BID } \\
(N=341)\end{array}$ & $\begin{array}{c}100 \mathrm{mg} \text { BID } \\
(\mathrm{N}=335)\end{array}$ & $\begin{array}{c}150 \mathrm{mg} \text { BID } \\
(\mathrm{N}=329)\end{array}$ & $\begin{array}{c}\text { All patients } \\
(\mathrm{N}=1005)\end{array}$ \\
\hline Race, Caucasian, $n(\%)$ & $333(97.7)$ & $321(95.8)$ & $318(96.7)$ & $972(96.7)$ \\
\hline Sex, female, $n(\%)$ & $182(53.4)$ & $167(49.9)$ & $184(55.9)$ & $533(53.0)$ \\
\hline Age [years], mean (range) & $74.2(51-92)$ & $73.8(50-92)$ & $73.6(48-94)$ & $73.9(48-94)$ \\
\hline Education [years], mean (range) & $14.1(0-25)$ & $13.9(0-25)$ & $14.1(0-25)$ & $14(0-25)$ \\
\hline${ }^{1}$ APOE4 genotype, at least 1 $\varepsilon 4$ allele, $n(\%)$ & $220(64.7)$ & $201(58.6)$ & $206(60.6)$ & $627(61.3)$ \\
\hline${ }^{2}$ ChEl use [months], mean (range) & $23.4(0.6-125.1)$ & $23.5(1.3-101.3)$ & $23.1(1.9-117.9)$ & $23.3(0.6-125.1)$ \\
\hline 2Memantine use [months], mean (range) & $12.8(1.5-67.1)$ & $12.4(1.0-34.1)$ & $11.6(0.9-42.4)$ & $12.3(0.9-67.1)$ \\
\hline ADAS-cog, mean (range) & $22.2(5.0-52.0)$ & $22.1(7.7-52.7)$ & $21.7(4.0-48.0)$ & $22.0(4.0-52.7)$ \\
\hline CDR-SB, mean (range) & $5.8(0.5-17.0)$ & $5.7(0.5-17.0)$ & $5.7(0.5-14.0)$ & $5.7(0.5-17.0)$ \\
\hline MMSE, mean (range) & $21.0(12.0-26.0)$ & $21.1(15.0-26.0)$ & $21.1(15.0-26.0)$ & $21.1(12.0-26.0)$ \\
\hline
\end{tabular}

${ }_{1}^{1}$ all-enrolled population, 2at randomization, ChEl - cholinesterase inhibitors, comparisons against Placebo based on one-way ANOVAs (continuous variables) and Cochran-Mantel-Haenszel (CMH) tests for general association (categorical variables)

the CDR-SB, compared to 31559.2 and 20030.3, respectively, for the planned models. The ADAS-cog adjusted model revealed a statistical trend for treatment effect in favour of the two tramiprosate groups ( $\mathrm{G} \times \mathrm{V}$ interaction: $P=0.098)$ while post-hoc planned contrasts showed lower changes from Baseline relative to placebo in the $100 \mathrm{mg}$ BID group at Week $26(P=0.065)$ and Week $52(P=0.090)$. The adjusted model for CDR-SB revealed no significant treatment effect ( $\mathrm{G} \times \mathrm{V}$ interaction: $P=0.505)$.

For $\mathrm{HV}$, the adjusted model showed an improved AIC of 3600.3 compared to 8139.1 for the planned model. The following covariates and covariate interactions were retained: Antidepressant Use, Vitamin E Use, Genotype, Cardiovascular Disease, Race, Type of ChEl Used, Total Intracranial Volume, Whole Brain Volume at Baseline, Baseline Hippocampus Volume $\times$ Treatment, Age Group $\times$ $\times$ Treatment, Genotype $\times$ Treatment, Race $\times$ $\times$ Treatment, Month $\times$ Genotype, Month $\times$ $\times$ Cardiovascular Disease, Month $\times$ Race, and Month $\times$ Total Intracranial Volume. The HV adjusted model showed a significant treatment effect $(P=0.011)$. Least square estimates of the mean $[95 \% \mathrm{Cl}]$ changes from Baseline were significantly different from zero for the placebo $\left(-419.3 \mathrm{~mm}^{3}\right.$ [-642.1 to $\left.\left.-196.4 \mathrm{~mm}^{3}\right] ; P<0.001\right)$ and $100 \mathrm{mg} \mathrm{BID}$ $\left(-135.1 \mathrm{~mm}^{3}\left[-249.5\right.\right.$ to $\left.\left.-20.7 \mathrm{~mm}^{3}\right] ; P=0.021\right)$ groups, while the change of $79.5 \mathrm{~mm}^{3}$ (-182.5 to $341.5 \mathrm{~mm}^{3}$ ) observed for the $150 \mathrm{mg}$ BID group was not $(P=0.550)$. The decrease in HV were significantly less than placebo for both the $100 \mathrm{mg}$ $(P=0.035)$ and $150 \mathrm{mg}(P=0.009)$ BID groups.

\section{Safety}

Table IV summarizes the most common adverse events (AE) and serious adverse events (SAE) of all causalities. The proportion of patients experiencing at least one AE for the placebo, $100 \mathrm{mg}$ BID and $150 \mathrm{mg}$ BID groups was $92.1 \%, 95.2 \%$ and $94.8 \%$, respectively. Nausea, syncope, vomiting, and weight decrease appeared to be dose-related. However, the incidence of these AEs in the $100 \mathrm{mg}$ BID group was not statistically different from placebo. A total of 255 patients (24.2\%) experienced at least one SAE with an incidence of $26.1 \%, 23.6 \%$ and $23.1 \%$, for the placebo, $100 \mathrm{mg}$ and $150 \mathrm{mg}$ BID groups, respectively. Syncope and pneumonia were among SAEs that appeared to be dose-related. Thirty-two (3.0\%) patients experienced an AE which resulted in death. Mortality rate was higher in the placebo group (4.0\%) compared to the $100 \mathrm{mg}(2.8 \%)$ and $150 \mathrm{mg}$ (2.3\%) BID groups. Gastrointestinal disorders were among the most frequent AEs that led to discontinuation, with a total of 38 (3.6\%) patients. When examining the AE profile among the most frequently occurring AEs that led to discontinuation, nausea (Placebo: 1 [0.3\%]; $100 \mathrm{mg}$ BID: 3 [0.9\%]; $150 \mathrm{mg}$ BID: 10 [2.9\%]) and vomiting (Placebo: 0 [0\%]; 100 mg BID: 4 [1.1\%]; 150 mg BID: 7 [2.2\%]) appeared to be dose-dependent events. Laboratory test results were generally unremarkable, with no apparent clinical differences between groups.

\section{Discussion}

In this trial of tramiprosate in mild-to-moderate $A D$, the planned analyses did not show statistically significant between-group differences. Significant Site effects and the impact of variables not included in the planned analyses reduced model fit and validity. In addition, reduced power due to withinand between-patient variance, as well as the unexpected low deterioration in the placebo group, render these analyses inconclusive. Results of the 


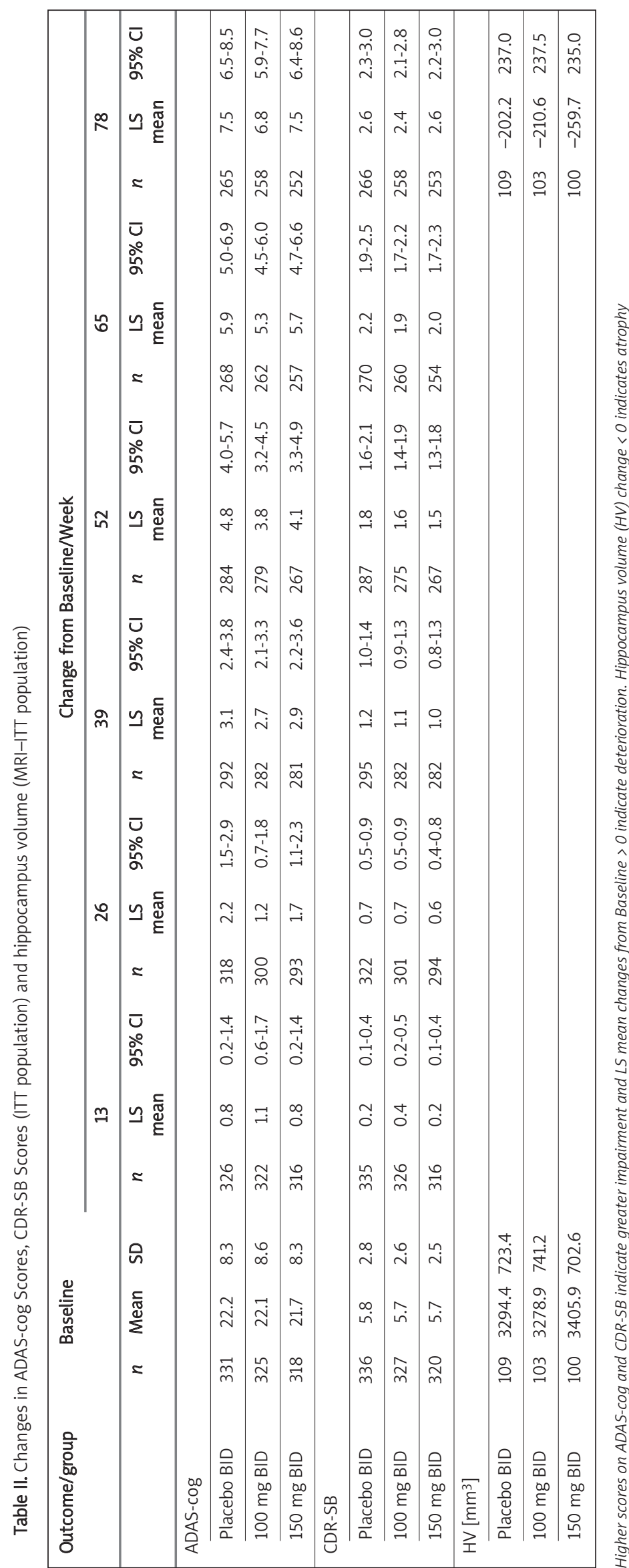

adjusted models, which improved statistical fit and reduced the impact of Site effects, revealed a statistical trend toward a treatment effect on cognition and a treatment-related reduction in HV loss. Overall, tramiprosate was well tolerated.

AD typically progresses from mild functional impairment to total dependence and death over a period of 5-20 years. A disease-modifying treatment initiated in the mild stage that slows progression by $25 \%$ would be expected to have a significant clinical impact. Consistent with this goal, and based on results from earlier trials, our study was powered to demonstrate a 2.5 point treatment effect on the ADAS-cog at 18 months. Although we had estimated an approximate 10-point deterioration in the placebo group, the 18-month nonadjusted and adjusted changes in ADAS-cog were only 7.4 points and 6.2 points, respectively. Accordingly, a $25 \%$ difference from placebo would be equivalent to an unadjusted change of 1.8 points and an adjusted change of 1.6 points. This trial was thus underpowered to detect a treatment effect, an issue of importance to other disease-modifying drug development programmes.

Statistical powering may also be affected by variance in longitudinal outcome measures that could obscure potential treatment signals and bias results toward the null hypothesis. In AD, many factors, such as concomitant medication type and dose, can affect outcome variability and their combined impact likely increases as trials become longer and involve larger cohorts. Simple ANCOVA models, such as those used in the planned analyses, may not have been sufficient to model unexplained variance arising from uncontrolled conditions. Indeed, the high unexplained variance found in the planned statistical models was the impetus for the development of more complex mixed-effects models that included multiple covariates and yielded improvement in modelling fit. This underscores the complexity of $A D$ and the importance of careful consideration of statistical modelling 
Table III. Change in ADAS-cog and CDR-SB (Adjusted Models) - ITT population

\begin{tabular}{|c|c|c|c|c|c|c|}
\hline \multirow[t]{3}{*}{ Visit / parameter } & \multicolumn{3}{|c|}{ ADAS-Cog } & \multicolumn{3}{|c|}{ CDR-SB } \\
\hline & Placebo BID & $100 \mathrm{mg}$ BID & $150 \mathrm{mg}$ BID & Placebo BID & $100 \mathrm{mg} \mathrm{BID}$ & $150 \mathrm{mg}$ BID \\
\hline & $(N=341)$ & $(N=335)$ & $(N=329)$ & $(N=341)$ & $(N=335)$ & $(N=329)$ \\
\hline Baseline/n & 331 & 325 & 318 & 336 & 327 & 320 \\
\hline Mean (SD) & $22.2(8.3)$ & $22.1(8.6)$ & $21.7(8.3)$ & $5.8(2.8)$ & $5.7(2.6)$ & $5.7(2.5)$ \\
\hline Week $13 / n$ & 297 & 295 & 293 & 302 & 299 & 295 \\
\hline LS mean change & -1.6 & -1.2 & -1.5 & 0.2 & 0.4 & 0.2 \\
\hline $95 \% \mathrm{Cl}$ & $-3.2 ;-0.0$ & $-2.8-0.4$ & $-3.0-0.1$ & $-0.2-0.7$ & $-0.1-0.8$ & $-0.3-0.6$ \\
\hline Difference (\%) vs. placebo & & $0.4(-25.0)$ & $0.1(-6.3)$ & & $0.2(100.0)$ & $0.0(0.0)$ \\
\hline$P$-value & & 0.302 & 0.761 & & 0.314 & 0.656 \\
\hline Week $26 / n$ & 294 & 277 & 277 & 296 & 281 & 276 \\
\hline LS mean change & -0.2 & -1.0 & -0.7 & 0.8 & 0.7 & 0.6 \\
\hline $95 \% \mathrm{Cl}$ & $-1.8-1.4$ & $-2.6-0.6$ & $-2.3-0.9$ & $0.3-1.2$ & $0.3-1.2$ & $0.2-1.1$ \\
\hline Difference (\%) vs. placebo & & $-0.8(400.0)$ & $-0.5(250.0)$ & & $-0.1(-12.5)$ & $-0.2(-25.0)$ \\
\hline$P$-value & & 0.065 & 0.223 & & 0.703 & 0.276 \\
\hline Week $39 / n$ & 265 & 264 & 264 & 268 & 266 & 265 \\
\hline LS mean change & 1.0 & 0.7 & 0.9 & 1.2 & 1.2 & 1.0 \\
\hline $95 \% \mathrm{Cl}$ & $-0.7-2.7$ & $-1.0-2.4$ & $-0.8-2.6$ & $0.7-1.7$ & $0.7-1.7$ & $0.5-1.5$ \\
\hline Difference (\%) vs. placebo & & $-0.3(-30.0)$ & $-0.1(-10.0)$ & & $-0.0(0.0)$ & $-0.2(-16.7)$ \\
\hline$P$-value & & 0.525 & 0.845 & & 0.721 & 0.329 \\
\hline Week $52 / n$ & 260 & 259 & 251 & 261 & 258 & 250 \\
\hline LS mean change & 3.1 & 2.0 & 2.3 & 2.0 & 1.8 & 1.7 \\
\hline $95 \% \mathrm{Cl}$ & $1.4-4.8$ & $0.4-3.7$ & $0.6-4.0$ & $1.5-2.5$ & $1.3-2.3$ & $1.2-2.2$ \\
\hline Difference (\%) vs. placebo & & $-1.1(-35.5)$ & $-0.8(-25.8)$ & & $-0.2(-10.0)$ & $-0.3(-15.0)$ \\
\hline$P$-value & & 0.090 & 0.193 & & 0.335 & 0.136 \\
\hline Week $65 / n$ & 246 & 243 & 236 & 247 & 244 & 237 \\
\hline LS mean change & 4.5 & 3.8 & 4.2 & 2.5 & 2.3 & 2.3 \\
\hline $95 \% \mathrm{Cl}$ & $2.8-6.3$ & $2.1-5.5$ & $2.5-5.9$ & $2.0-3.0$ & $1.8-2.8$ & $1.8-2.8$ \\
\hline Difference (\%) vs. placebo & & $-0.7(-15.6)$ & $-0.3(-6.7)$ & & $-0.2(-8.0)$ & $-0.2(-8.0)$ \\
\hline$P$-value & & 0.217 & 0.535 & & 0.280 & 0.378 \\
\hline Week $78 / n$ & 248 & 242 & 229 & 245 & 243 & 233 \\
\hline LS mean change & 6.2 & 5.4 & 6.3 & 3.0 & 2.7 & 3.0 \\
\hline $95 \% \mathrm{Cl}$ & $4.5-7.9$ & $3.6-7.1$ & $4.6-8.0$ & $2.5-3.5$ & $2.2-3.2$ & $2.5 ; 3.5$ \\
\hline Difference (\%) vs. placebo & & $-0.8(-12.9)$ & $0.1(1.6)$ & & $-0.3(-10.0)$ & $0.0(0.0)$ \\
\hline$P$-value & & 0.174 & 0.873 & & 0.232 & 0.915 \\
\hline
\end{tabular}

Higher scores on ADAS-Cog and CDR-SB indicate greater impairment and LS mean changes from Baseline > 0 indicate deterioration. The following covariates and covariate interactions were retained in the adjusted ANCOVA Models. ADAS-cog: Race, Type of ChEI Used, Age (quartiles), Disease Severity, Vitamin E dose, Antidepressant Use, Genotype, Visit X Disease Severity, Visit X Age (quartiles), and Visit X Memantine Dose. CDR-SB: Cardiovascular Disease, Type of ChEI Used, Disease Severity, Memantine Use, Years of Education (quartiles), Antidepressant Use, Genotype, Vitamin E Use, and Visit X Disease Severity

aimed at improving statistical fit and validity of results.

Results of the HV analysis illustrate the importance of statistical modelling. Our planned analysis showed a trend toward greater HV loss in the $150 \mathrm{mg}$ BID tramiprosate group, a finding consistent with the AN-1792 amyloid vaccine trial, which showed a non-significantly greater HV loss in the antibody responders [26]. While the underlying neurological basis of the HV loss in the 
Table IV. Most common adverse events (> 5\%) and serious adverse events (> 1\%) in any treatment group, all causalities, safety population

\begin{tabular}{|c|c|c|c|}
\hline Preferred term (PT) & $\begin{array}{c}\text { Placebo } \mathrm{BID}(N=353) \\
n(\%)\end{array}$ & $\begin{array}{c}100 \mathrm{mg} \mathrm{BID}(N=352) \\
n(\%)\end{array}$ & $\begin{array}{c}150 \mathrm{mg} \mathrm{BID}(N=347) \\
n(\%)\end{array}$ \\
\hline \multicolumn{4}{|l|}{ Adverse events } \\
\hline Fall & $51(14.4)$ & $58(16.5)$ & $45(13.0)$ \\
\hline Depression & $43(12.2)$ & $29(8.2)$ & $33(9.5)$ \\
\hline Nausea & $42(11.9)$ & $58(16.5)$ & $75(21.6)$ \\
\hline Diarrhoea & $41(11.6)$ & $41(11.6)$ & $49(14.1)$ \\
\hline Dizziness & 39 (11.0) & $50(14.2)$ & 38 (11.0) \\
\hline Urinary tract infection & 39 (11.0) & $38(10.8)$ & $32(9.2)$ \\
\hline Upper respiratory tract infection & $34(9.6)$ & $27(7.7)$ & $32(9.2)$ \\
\hline Agitation & $31(8.8)$ & $34(9.7)$ & $26(7.5)$ \\
\hline Headache & $29(8.2)$ & $25(7.1)$ & $28(8.1)$ \\
\hline Vomiting & $28(7.9)$ & $33(9.4)$ & $47(13.5)$ \\
\hline Fatigue & $25(7.1)$ & $26(7.4)$ & $23(6.6)$ \\
\hline Back Pain & $25(7.1)$ & $23(6.5)$ & $23(6.6)$ \\
\hline Weight decrease & $24(6.8)$ & $38(10.8)$ & $52(15.0)$ \\
\hline Insomnia & $23(6.5)$ & $18(5.1)$ & $16(4.6)$ \\
\hline Cough & $22(6.2)$ & $16(4.5)$ & $16(4.6)$ \\
\hline Nasopharyngitis & $21(5.9)$ & $22(6.3)$ & $18(5.2)$ \\
\hline Anxiety & $20(5.7)$ & $21(6.0)$ & $17(4.9)$ \\
\hline Syncope fainting & $13(3.7)$ & $19(5.4)$ & $25(7.2)$ \\
\hline \multicolumn{4}{|l|}{ Serious adverse events } \\
\hline Syncope & $9(2.5)$ & $10(2.9)$ & $13(3.8)$ \\
\hline Congestive cardiac failure & $7(2.0)$ & $4(1.1)$ & $1(0.3)$ \\
\hline Fall & $4(1.1)$ & $5(1.4)$ & $1(0.3)$ \\
\hline Myocardial infarction & $4(1.1)$ & $2(0.6)$ & $0(0.0)$ \\
\hline Pneumonia & $2(0.6)$ & $4(1.1)$ & $8(2.3)$ \\
\hline
\end{tabular}

MedDRA (Version 9.0) was used. PT presented in decreasing order of incidence in the placebo group. Patients are counted once per PT using the most severe level for that event. For some PT, incidence may be derived from more than one System Organ Class

vaccine trial remains unclear, inclusion of covariates selected on the basis of clinical relevance and statistical significance in our trial reversed the direction of the between-group difference, with no change in HV in the $150 \mathrm{mg}$ BID group and a lower volume change relative to placebo in the $100 \mathrm{mg}$ BID group. Interestingly, the adjusted model identified a significant interaction between treatment and several covariates, specifically, age, hippocampus volume at baseline and APOE genotype. These variables have previously been found to exert an impact on HV in a number of longitudinal imaging studies [27-29]. Our study suggests that these variables may modulate the effects of an anti-amyloid intervention on HV changes over the course of the trial. Confirmation of the impact of the above covariates and their interaction with treatment in other data sets would corroborate our findings and allow the development of more complex imaging analysis plans in future trials.

In our study, we did not find close agreement between cognitive/clinical and HV changes. Psychometric tests and VMRI may not measure precisely the same disease processes, and changes in biological and cognitive measures may not occur over the same time period [17, 30]. Nevertheless, volumetric MRI and cognitive measures are complementary and may be implemented in AD trials in order to document potential treatment effects on the underlying disease and to provide regulatory support for disease modification claims.

This trial is among the first published Phase III trials of anti-amyloid compounds for the treatment of AD. Planned analyses did not demonstrate statistically significant between-group differences, 
but were confounded by weakness of the statistical models. Post-hoc adjusted analyses showed a treatment effect in reducing HV loss and a trend toward reduced cognitive decline. These results must be interpreted in consideration of the limitations of the outcome measures, the heterogeneity of the disease and the impact of demographic, genetic and clinical variables on patient outcome.

\section{Acknowledgments}

The authors wish to thank all patients and their families who took part in the trial. They also wish to acknowledge the Alphase Investigators for their contributions in conducting the study. From the United States: Paul S. Aisen, Tom Ala, Stephen Aronson, B. Ashok Raj, Roberta Ball, Jose De La Gandara, Steven T. DeKosky, Juan Espinosa, Robert G. Feldman, Steven Ferris, Stephen Flitman, Jose Gamez, Gary Gerard, J. Goldstein, Norman Gordon, Sanjay Gupta, Lindy Harrell, Mark Harris, Richard Holub, James Kimball, Louis Kirby, Chandra Krishnasastry, Alan Lerner, Jary Lesser, David Ira Margolin, Jacobo E Mintzer, Leslie Moldauer, Eric Pfeiffer, Nunzio Pomara, Anton Porsteinsson, Ralph Richter, Joel Ross, Barry Rovner, Donald Royall, Carl Sadowsky, Stephen Salloway, Frederick Schaerf, Fred Sheftell, Ram Shrivastava, Bart Sloan, Paul Solomon, Reisa Sperling, Mary Stedman, Susan J. Steen, Joel Streim, Stephen Thein, Michael Tuchman, Larry Tune, C. van Dyck, Richard Weisler. From Canada: Peter Bailey, Michael Borrie, Remi W. Bouchard, Howard Chertkow, Sharon Cohen, Angeles Garcia, Serge Gauthier, Marcel Germain, Danilo Antonio Guzman, Nathan Herrmann, David Hogan, Jack Kooy, Chris MacKnight, Giovanni Marotta, Ziad Nasreddine, Emmanuelle Pourcher, Alain Robillard.

\section{References}

1. Gandy S. The role of cerebral amyloid $\beta$ accumulation in common forms of Alzheimer disease. J Clin Invest 2005; 115: 1121-9.

2. Canevari L, Abramov A, Duchen MR. Toxicity of amyloid $B$ peptide: tales of calcium, mitochondria, and oxidative stress. Neurochem Res 2004; 29: 637-50.

3. Schaller BJ. Strategies for molecular imaging dementia and neurodegenerative diseases. Neuropsychiatr Dis Treat 2008; 4: 585-612.

4. Citron M. Strategies for disease modification in Alzheimer's disease. Nat Rev Neurosci 2004; 5: 677-85.

5. Gervais F, Paquette J, Morissette C, et al. Targeting soluble Abeta peptide with Tramiprosate for the treatment of brain amyloidosis. Neurobiol Aging 2007; 28: 537-47.

6. Krzywkowski P, Sebastiani G, Williams S, et al. Tramiprosate Prevents Amyloid Beta-induced Inhibition of Long-term Potentiation in Rat Hippocampal Slices. $8^{\text {th }}$ International Conference AD/PD, Salzburg, Austria, March 14-18, 2007.

7. Azzi M, Morissette C, Fallon L, et al. Involvement of both GABA-dependent and -independent pathways in trami- prosate neuroprotective effects against amyloid-beta toxicity. $8^{\text {th }}$ International Conference AD/PD, Salzburg, Austria, March 14-18, 2007.

8. Aisen PS, Saumier D, Briand R, et al. A Phase II study targeting amyloid-beta with 3APS in mild-to-moderate Alzheimer disease. Neurology 2006; 67: 1757-63.

9. American Psychiatric Association. Diagnostic and Statistical Manual of Mental Disorder, Fourth Edition, Text Revision. Washington, DC: American Psychiatric Association, 2000.

10. McKhann G, Drachman D, Folskein M, Katzman R, Price D, Stadlan EM. Clinical diagnosis of Alzheimer's disease: report of the NINCDS-ADRDA Word Group under the auspices of Department of Health and Human Services Task Force on Alzheimer's Disease. Neurology 1984; 34: 939-44.

11. Folstein MF, Folstein SE, McHugh PR. "Mini-Mental State" a practical method for grading the cognitive state of patients for the clinician. Psychiatr Res 1975; 12: 189-98.

12. Mohs RC, Cohen L. Alzheimer's Disease Assessment Scale (ADAS). Psychopharmacol Bull 1988; 24: 627-8.

13. Morris JC. The Clinical Dementia Rating (CDR): current version and scoring rules. Neurology 1993; 43: 2412-4.

14. Schneider LS, Olin JT, Doody RS, et al. Validity and Reliability of the Alzheimer's Disease Cooperative StudyClinical Global Impression of Change. Alzheimer Dis Assoc Disord 1997; 11 (Suppl. 2): S22-S32.

15. Cummings JL. The Neuropsychiatric inventory: assessing psychopathology in dementia patients. Neurology 1997; 48: S10-S16.

16. Gélinas I, Gauthier L, McIntyre M, Gauthier S. Development of a functional measure for persons with Alzheimer's disease: the disability assessment for dementia. Am J Occup Ther 1999; 53: 471-81.

17. Gauthier S, Aisen PS, Ferris SH, et al. Effect of tramiprosate in patients with mild-to-moderate Alzheimer's disease: exploratory analyses of the MRI sub-group of the Alphase study. J Nutr Health Aging 2009; 13: 550-7.

18. Hsu YY, Schuff N, Du AT, et al, Comparison of automated and manual MRI volumetry of hippocampus in normal aging and dementia. J Magn Reson Imaging 2002; 16: 305-10.

19. Aisen PS, Schafer KA, Grundman M, et al. Effects of rofecoxib or naproxen vs. placebo on Alzheimer disease progression: a randomized controlled trial. JAMA 2003; 289:2819-26.

20. Csernansky JG, Wang L, Joshi S, et al. Early DAT is distinguished from aging by high-dimensional mapping of the hippocampus. Neurology 2000; 55: 1636-43.

21. Dickerson BC, Goncharova I, Sullivan MP, et al. MRIderived entorhinal and hippocampal atrophy in incipient and very mild Alzheimer's disease. Neurobiol Aging 2001; 22: 747-54

22. Du AT, Schuff N, Amend D, et al. Magnetic resonance imaging of the entorhinal cortex and hippocampus in mild cognitive impairment and Alzheimer's disease. J Neurol Neurosurg Psychiatry 2001; 71: 441-7.

23. Ezekiel F, Chao L, Kornak J, et al. Comparisons between global and focal brain atrophy rates in normal aging and Alzheimer's disease. Alzheimer Dis Assoc Disord 2004; 18: 196-201.

24. Jack CR Jr, Petersen, RC, Xu Y, et al. Rates of hippocampal atrophy correlate with change in clinical status in aging and AD. Neurology 2000; 55: 484-90.

25. Jack CR Jr, Slomkowski M, Gracon S, et al. MRI as a biomarker of disease progression in a therapeutic trial of melameline for AD. Neurology 2003; 60: 253-60. 
26. Fox NC, Black RS, Gilman, $S$, et al. Effects of $A \beta$ immunization (AN1792) on MRI measures of cerebral volume in Alzheimer disease. Neurology 2005; 64: 1563-72.

27. Hashimoto M, Kazui H, Matsumoto K, et al. Does donepezil treatment slow the progression of hippocampal atrophy in patients with Alzheimer's disease? Am J Psychiatry 2005; 162: 676-82.

28. Moffat SD, Szekely CA, Zonderman AB, et al. Longitudinal change in hippocampal volume as a function of apolipoprotein E genotype. Neurology 2000; 55: 134-6.

29. Mueller SG, Weiner MW. Selective effect of age, Apo e4, and Alzheimer's disease on hippocampal subfields. Hippocampus 2009; 19: 558-64.

30. Saumier D, Aisen PS, Gauthier S, et al. Lessons learned in the use of volumetric MRI in therapeutic trials in Alzheimer's disease: the ALZHEMED (Tramiprosate) experience. J Nutr Health Aging 2009; 13: 370-2. 